\title{
The effects of a newsletter on bedding control on house dust mite allergen concentrations in childcare centers in Korea
}

\author{
Jeonghoon Kim ${ }^{1,2}$, Kyoung Yong Jeong ${ }^{3}$, Ho-Jang Kwon ${ }^{4}$, Heasuk Yang ${ }^{1}$, Hye Yung Yum ${ }^{5}$, \\ Seon Ah Lee ${ }^{1}$, Chae-Bong Kim ${ }^{1,6}$, Hyunjung Kim ${ }^{1,5}$, Wan Ryung Lim ${ }^{1}$, Soyoung Hong ${ }^{1,7}$, \\ Kyoosang $\mathrm{Kim}^{1}$ \\ ${ }^{1}$ Department of Environmental Health Research, Seoul Medical Center, Seoul; ${ }^{2}$ Department of Environmental Health, \\ Graduate School of Public Health, Seoul National University, Seoul; ${ }^{3}$ Department of Internal Medicine and Institute of Allergy, \\ Yonsei University College of Medicine, Seoul; ${ }^{4}$ Department of Preventive Medicine, Dankook University College of Medicine, \\ Cheonan; ${ }^{5}$ Atopy Asthma Center, Seoul Medical Center, Seoul; ${ }^{6}$ Department of Public Health, Graduate School of Public \\ Health, Korea University, Seoul; ${ }^{7}$ Department of Public Health Nutrition, Graduate School of Public Health, Seoul National \\ University, Seoul, Korea
}

\begin{abstract}
Objectives Bedding in childcare centers (CCCs) can hold house dust mite (HDM) allergens. This study examined whether HDM allergen levels can be reduced through the distribution of an educational newsletter on bedding control to parents of CCC children in Korea. Methods All 38 CCCs were measured for Der 1 (sum of Der $f_{1}$ and Der $p$ 1) concentrations on classroom floors and bedding before the intervention. Educational newsletters on children's bedding control were sent to 21 CCCs by mail, and teachers were asked to distribute the newsletters to the parents of the children (intervention group). The remaining 17 CCCS were not sent newsletters (control group). The measurement of Der 1 concentrations in 38 CCCs was repeated after the intervention. Dust samples were collected with a vacuum cleaner and analyzed using enzyme-linked immunosorbent assay methods.

Results The Der 1 concentrations on the bedding were significantly higher than those on the floors in 38 CCCs at baseline $(p<0.05)$. Although changes of the Der 1 concentrations for the control group $(n=17)$ were not significant, Der 1 concentrations for the intervention group $(n=21)$ decreased significantly from $2077.9 \mathrm{ng} / \mathrm{g}$ dust to $963.5 \mathrm{ng} / \mathrm{g}$ dust on the floors and from $3683.9 \mathrm{ng} / \mathrm{g}$ dust to $610.4 \mathrm{ng} / \mathrm{g}$ dust on bedding $(p<0.05)$. Conclusions The distribution of educational newsletters on bedding control to parents may be an effective means of controlling HDMs in CCCs.
\end{abstract}

Keywords: Childcare center, Der f 1, Der p 1, Educational newsletter, House dust mite, Intervention

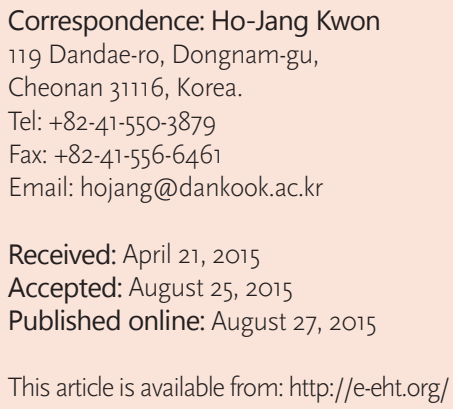

This article is available from: http://e-eht.org/

\section{Introduction}

Exposure to indoor allergens is a risk factor for developing allergies and asthma symptoms among sensitive children [1]. Although direct associations between allergen exposure and the development of sensitization of allergy and asthma have not been confirmed, indoor allergens play important roles in triggering and worsening allergic and respiratory symptoms [2]. Because children are more susceptible to indoor allergen sensitization during the first three years of life, it is important that 
children avoid allergens during the early stages of their lives [3].

To date, young children tend to spend large portions of their time in childcare centers (CCCs) because of the increased number of double-income and single-parent families. A recent report showed that the number of CCCs in Korea increased by approximately 49\% from 2000 to 2010 [4]. Approximately 42\% of young Korean children between the ages of zero and six had entered a CCC in 2011. In Seoul, approximately 37\% of young children attend CCCs.

Young children who attend CCCs can be exposed to high levels of indoor allergens. A previous study measured indoor allergens in the home, CCCs, schools, and hospitals in Singapore [5]. This study reported that although Der $\mathrm{p} 1$ and Der $\mathrm{f} 1$ concentrations in schools and CCCs were lower than in the home environment, several cases exceeded threshold levels of 2000 ng/g dust. A study in Tampa, Florida showed that Der $\mathrm{p} 1$ and/ or Der $\mathrm{f} 1$ were detected in 10 of 20 daycare centers (DCCs) and 8 DCCs had house dust mite (HDM) allergens levels of $>2000$ ng/g dust [6].

Although allergen levels in CCCs have been reported in other countries, such as Germany [7], the United States [6], Sweden [8], Brazil [9], and Singapore [5], the allergen levels in Korean CCCs have not been thoroughly examined. Several HDM allergen control strategies, such as bed and pillow encasement, the use of vacuum cleaners equipped with high-efficiency particulate air filters, dry steam cleaning, laundry washing with hot wa- ter $\left(>55^{\circ} \mathrm{C}\right)$, solar exposure, and maintaining indoor relative humidity at $35 \%$ to $50 \%$ have been introduced $[1,10-15]$. However, these allergen control strategies may be difficult and costly to apply in CCCs that manage high population densities.

Educational newsletters can serve as an accessible medium for delivering information to parents. Because bedding in most CCCs in Seoul is laundered in children's homes, newsletters on bedding management may be used to control HDMs. However, to the best of our knowledge, no previous studies have examined whether newsletters are a genuinely effective method for mitigating or controlling dust mite allergens. A previous study reported that repetitive health education to the housekeepers was shown to decrease the mite abundance and cockroach infestation rate in homes in Seoul [16]. The purpose of this study was to determine whether the HDM allergen levels can be reduced through the distribution of an educational newsletter on bedding control to the parents of children in CCCs in Korea.

\section{Materials and Methods}

\section{Study Design and Recruitment}

The subjects included in this study were recruited from the Seoul Atopy Free School as part of the Atopy Free Seoul Project in Seoul. A total of 358 kindergartens including CCCs participated in the project in 2012. Of the 358 facilities, 40 CCCs were recruited to assess the comprehensive indoor environment in-

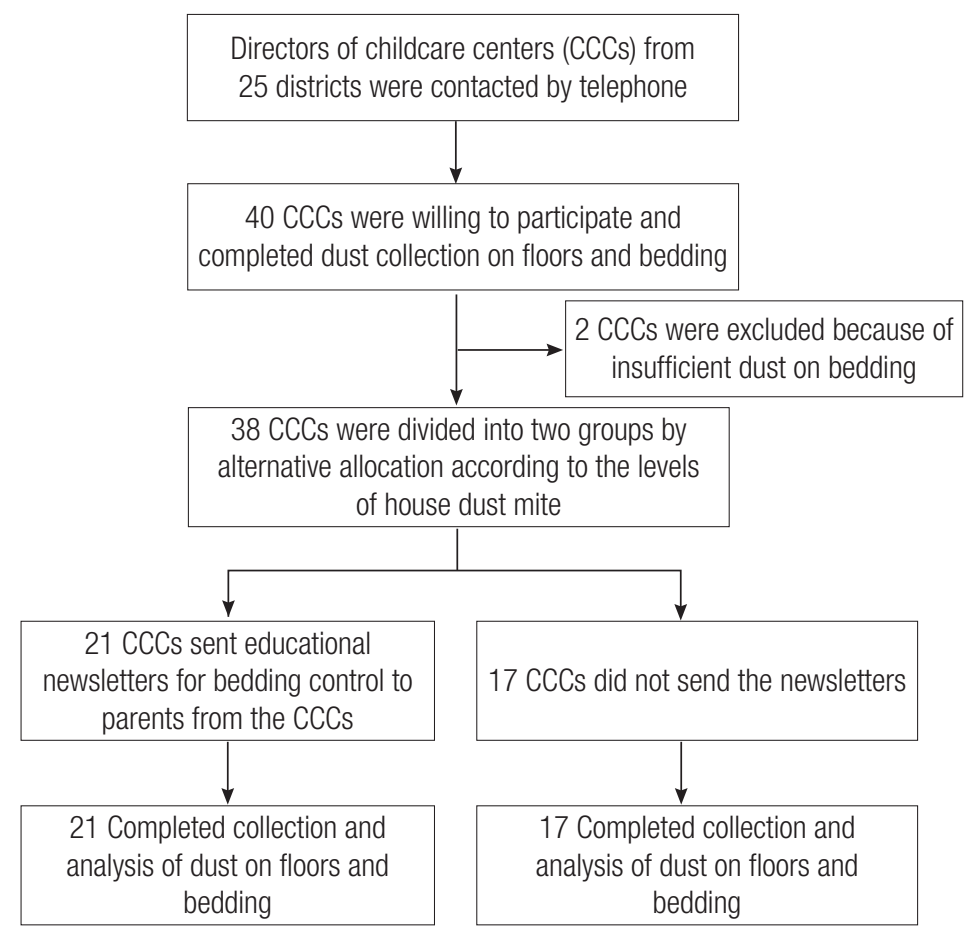

Figure 1. Flow chart of childcare center recruitment, dust collection and intervention procedures. 
cluding the HDM allergen levels in classrooms and to offer feedback to make a better indoor environment as part of the project. A flow chart of the recruitment, dust collection and intervention procedures carried out at the CCCs is presented in Figure 1. The research team aimed to recruit one to two CCCs in each of the 25 districts to participate in the study. The directors of 40 CCCs across 24 districts expressed an interest in participating.

To estimate the HDM allergen concentrations, the research team visited CCCs and collected dust from the floors and bedding in 40 CCCs from July 23, 2012 to October 26, 2012 (summer to autumn season; first phase). The bedding in this study included blankets and bedclothes that children used while taking naps after lunch in the CCCs. Two CCCs were excluded because the bedding dust samples were insufficient for estimating the HDM allergen concentrations. A total of 38 CCCs were included in the subsequent investigation.

After this first phase, the CCCs were divided into the intervention and control groups by alternate allocation according to the levels of the HDM on bedding. The research team sent 30 copies of educational newsletters on children's bedding control by mail to 21 of the 38 CCCs (intervention group) during the first week in December of 2012. Childcare teachers were asked to distribute the newsletters to the parents of the children cared for in the classrooms where dust was collected. The remaining 17 CCCs were not sent the newsletters (control group).

Samples of floor and bedding dust were collected again at same site from the 38 CCCs from January 7, 2013 to February 8, 2013 (winter season; second phase) after the intervention. All of the floor and bedding dust samples collected during this second phase were tested to determine their HDM allergen concentrations.

\section{Dust Sampling}

Floor dust was collected from the two classrooms assigned to the youngest children (zero to five years of age) in each CCC. Dust was collected from the entire classroom floor area. Most CCCs in Korea are built from with hard flooring materials and do not commonly use carpets. For child safety purposes, several CCCs spread bedding or soft poly vinyl carbonate mats over sections of the floor areas. In the CCCs where bedding sheets or mats were spread over the floors, the field technician moved these to a corner of the room and collected dust from the hard flooring material. Bedding dust was collected from above and underneath six to seven bedding sets in the targeted classrooms. During the dust-sampling phase, field technicians collected information on the facility type, the total number of children served, the type of floor material, the weekly frequency of cleaning in classrooms, the year of CCC construction, the number of nearest traffic lanes, and the presence of a bus garage within 2 $\mathrm{km}$ from the CCCs were recorded. In the target classrooms, the number and age of children that use the target classrooms were recorded.

A vacuum cleaner (1050 Watts) (VC-PU521; Samsung, Seoul, Korea) equipped with a suction tool was used to collect the floor and bedding dust samples. The dust was vacuumed through a non-woven filter (pore size of $0.3 \mu \mathrm{m}$ ) installed to the rear of the suction tool. This specific dust collection method has been described in previous studies [17]. Each dust sample was sealed in a plastic container and then sent to Institute of Allergy (College of Medicine Yonsei University) laboratories.

\section{Estimation of House Dust Mite Allergen Levels}

The dust samples were strained through $425-\mu \mathrm{m}$ testing sieves and then weighed to obtain a mass of $100 \mathrm{mg}$. The extracted dust samples in phosphate buffered saline ( $\mathrm{pH} 7.4)$ with $1 \%$ bovine serum albumin and $0.05 \%$ Tween 20 were assayed using Der $\mathrm{f} 1$ and Der $\mathrm{p} 1$ ELISA kits (EL_DF1, EL_DP1, Indoor Biotechnologies Inc., Charlottesville, VA, USA). The HDM allergen concentrations below the detection limits were assigned a value of $25 \mathrm{ng} / \mathrm{g}$ dust (half of the lowest detectable concentration).

\section{Evaluating the Reductions in Tween House Dust Mite Allergen Concentrations Due to Newsletters}

The newsletters included a definition of HDMs, including pictures of dust mites, descriptions of areas where mites thrive, health effects of exposure to mite allergens, and bedding laundering methods (Figure 2). The laundering procedure was described as follows: 1) wash your children's bedding with hot water $\left.\left(>55^{\circ} \mathrm{C}\right) ; 2\right)$ dry the laundry completely in the sun; and 3$)$ beat dirt and dead skin cells from the dried laundry. The CCC teachers reported the status of the newsletter distribution during the second dust-sampling period.

\section{Statistical Analysis}

The Der 1 concentrations on the floors and bedding were calculated by adding the Der $\mathrm{f} 1$ and Der $\mathrm{p} 1$ concentrations $[7,9]$. The normality of the data distribution was verified through the Kolmogorov-Smirnov test. The HDM allergen concentrations were log-transformed prior to statistical analysis due to their approximately lognormal distributions. Paired $t$-tests were used to compare the HDM allergen concentrations found on the floors with those found on the bedding. Simple linear regression methods were used to assess the relationship between the Der 1 concentrations on the floors and bedding. Student's $t$-test was employed to compare Der 1 levels on floor and bedding and on CCC characteristics. Because the differences of Der 1 concen- 
$\underline{\text { Educational Newsletters }}$

Eliminating house dust mites on children's bedding

\section{What is house dust mites?}

- House dust mites are an important cause of worsening allergic diseases, such as atopic dermatitis and asthma in indoor environments

- The most well-developing room temperature and relative humidities are $25 \sim 28^{\circ} \mathrm{C}$ and $64 \sim 75 \%$

- House dust mites are found in products made of cloth, such as bedding, mattresses, clothes, and carpeting

\section{Management of dust mites on bedding}

1) Washing: wash your children's bedding with hot water $\left(>55^{\circ} \mathrm{C}\right)$

2) Drying: dry the laundry completely in the sun

3) Beating: beat the dirt or dead skin cells from the dried laundry

Control children's atopic diseases

through improved bcdding managcment

Figure 2. Educational newsletters on bedding control distributed to the parents of children enrolled in childcare centers.

trations before and after the intervention were not normally distributed, the Wilcoxon signed-rank test was conducted for paired comparisons of the Der 1 concentrations before and after the intervention. The Wilcoxon rank-sum test was applied to compare the Der 1 concentrations between the intervention and control groups because distributions of Der 1 concentrations in each group were not normal. SAS version 9.2 (SAS Institute Inc., Cary, NC, USA) was used to conduct the statistical analyses. A significance level of 0.05 was applied to all of the procedures. SigmaPlot version 9.0 (Systat Software Inc., Chicago, IL, USA) was used to draw a graph. Microsoft Office Power Point 2007 (Microsoft Corp., Redmond, WA, USA) was used to create charts and newsletters, respectively.

\section{Results}

\section{Detection Rates and House Dust Mite Allergen Levels at Baseline}

In $33(87 \%)$ and six (16\%) of the 38 CCCs, detectable levels of Der $\mathrm{f} 1$ and Der $\mathrm{p} 1$ were found on the floors during the first phase, respectively. In 37 (97\%) and eight (21\%) of the 38 CCCs, detectable levels of Der $\mathrm{f} 1$ and Der $\mathrm{p} 1$ were found on

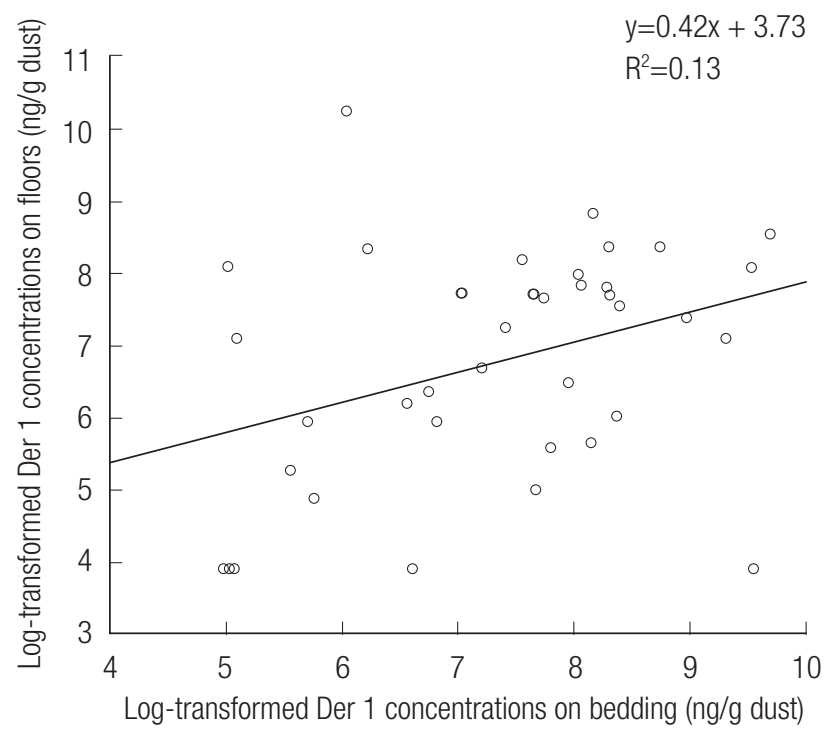

Figure 3. Correlation between log-transformed Der 1 concentrations on the floors and bedding in 38 childcare centers.

the bedding, respectively.

Geometric means (GMs) of the Der f 1, Der p1, and Der 1 concentrations on the floors were $716.6 \mathrm{ng} / \mathrm{g}$ dust (geometric standard deviation $[\mathrm{GSD}]=6.0), 36.4 \mathrm{ng} / \mathrm{g}$ dust $(\mathrm{GSD}=2.7)$, and $879.2 \mathrm{ng} / \mathrm{g}$ dust $(\mathrm{GSD}=5.0)$, respectively. The GM of Der f 1 , Der p1, and Der 1 concentrations on the bedding were $1392.5 \mathrm{ng} / \mathrm{g}$ dust $(\mathrm{GSD}=4.7), 38.0 \mathrm{ng} / \mathrm{g}$ dust $(\mathrm{GSD}=2.4)$, and $1551.1 \mathrm{ng} / \mathrm{g}$ dust $(\mathrm{GSD}=4.0)$, respectively.

\section{Factors Associated with House Dust Mite Allergen Levels}

The Der 1 concentrations on the floors were significantly higher than the Der 1 concentrations on the bedding in 38 CCCs $(p<0.05)$. The log-transformed Der 1 concentrations found on the floors and bedding in the $38 \mathrm{CCC}$ were correlated $\left(\mathrm{R}^{2}=0.13\right)$ (Figure 3).

Characteristics of 38 CCCs and Der 1 concentrations on the floors and bedding are presented in Table 1 . The Der 1 concentrations found on the floors and bedding were not significantly associated with CCC characteristics.

\section{Effects of an Educational Newsletter on House Dust Mite Allergen Level Reduction}

All of the teachers in 21 of 38 CCCs studied reported that they had successfully distributed the newsletters to the parents of the children from the targeted classrooms. The pre-intervention and post-intervention Der 1 concentrations on the floors and bedding were significantly different $(p<0.05)$ (Table 2$)$. The arithmetic mean (AM) of Der 1 concentrations on the floors and bedding in the intervention group $(\mathrm{n}=21)$ reached $2077.9 \pm 1886.1 \mathrm{ng} / \mathrm{g}$ 
Table 1. Characteristics of childcare centers and their associations with Der 1 concentrations (ng/g dust) on floors and bedding

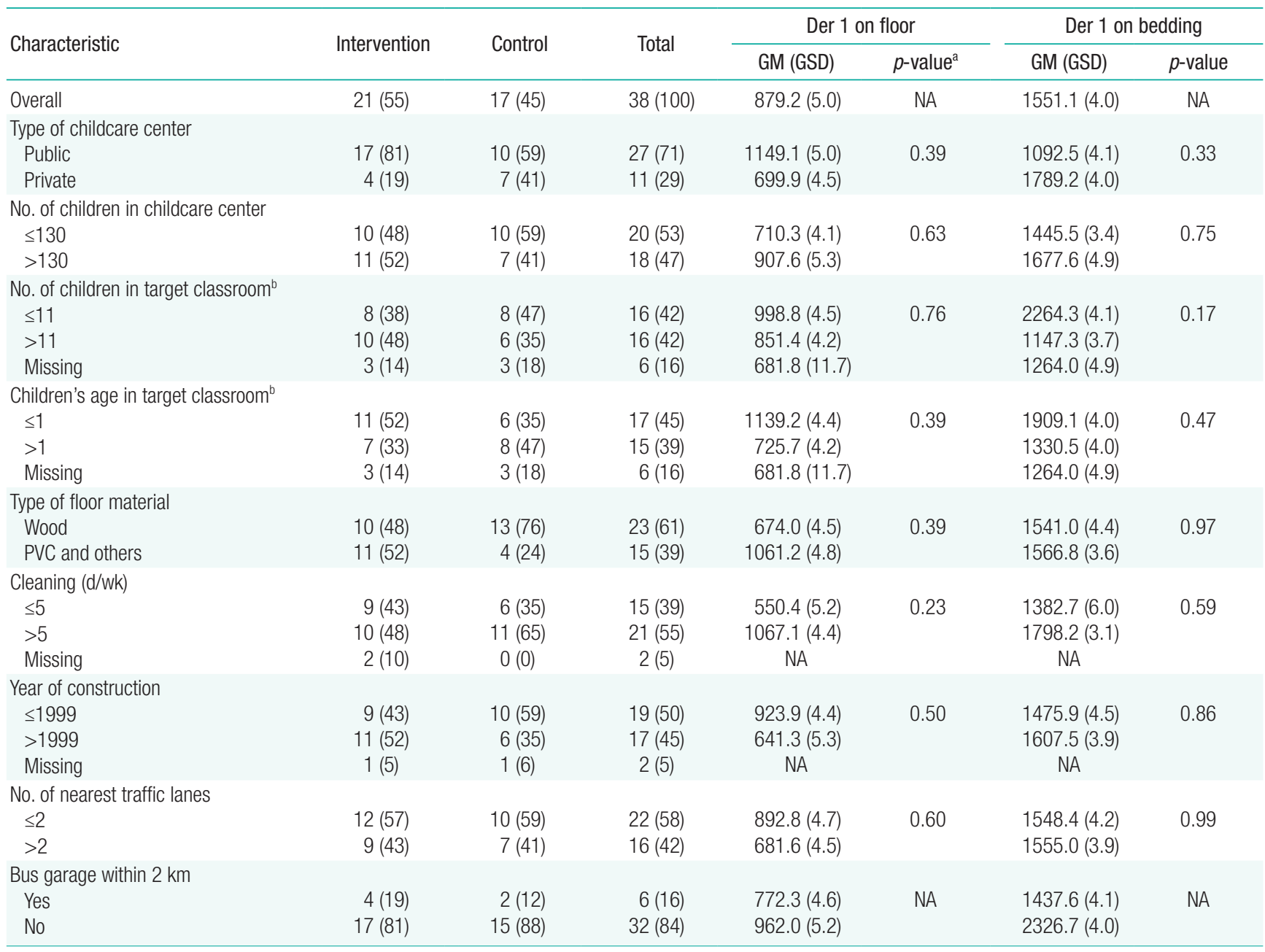

Values are presented as number (\%).

GM, geometric mean; GSD, geometric standard deviation; NA, not applicable; PVC, poly vinyl carbonate.

${ }^{a} p$-value by Student's $t$-test.

${ }^{\mathrm{b}}$ The average number and age of the children in the two classrooms where house dust mite allergen measurements were performed were calculated.

Table 2. Pre-and post-intervention Der 1 concentrations on floors and bedding (ng/g dust)

\begin{tabular}{|c|c|c|c|c|c|}
\hline & \multirow{2}{*}{ Group } & \multirow{2}{*}{$\mathrm{n}$} & Pre-intervention & Post-intervention & \multirow{2}{*}{$p$-value } \\
\hline & & & $\mathrm{AM} \pm \mathrm{SD}$ & $\mathrm{AM} \pm \mathrm{SD}$ & \\
\hline \multirow[t]{3}{*}{ Floor } & Intervention & 21 & $2077.9 \pm 1886.1$ & $963.5 \pm 1480.4$ & $<0.01$ \\
\hline & Control & 17 & $2885.6 \pm 6757.8$ & $1150.8 \pm 2422.4$ & 0.12 \\
\hline & $p$-value ${ }^{b}$ & & 0.31 & 0.97 & \\
\hline \multirow[t]{2}{*}{ Bedding } & Intervention & 21 & $3683.9 \pm 4645.6$ & $610.4 \pm 856.4$ & $<0.001$ \\
\hline & Control & 17 & $2929.3 \pm 3397.6$ & $2819.1 \pm 5601.4$ & 0.23 \\
\hline
\end{tabular}

$\mathrm{AM}$, arithmetic mean; SD, standard deviation.

${ }^{a} p$-value between pre- and post-intervention, Wilcoxon signed-rank test.

${ }^{\mathrm{b}} p$-value between intervention and control group, Wilcoxon rank-sum test.

dust and $3683.9 \pm 4645.6 \mathrm{ng} / \mathrm{g}$ dust, respectively, at the time of pre-intervention, and these values decreased to $963.5 \pm 1480.4$ $\mathrm{ng} / \mathrm{g}$ dust and $610.4 \pm 856.4 \mathrm{ng} / \mathrm{g}$ dust, respectively, after intervention. However, the Der 1 concentrations on the floors and bedding of the control group did not change significantly. The
AM of Der 1 concentrations on the floors and bedding in the control group $(\mathrm{n}=17)$ were $2885.6 \pm 6757.8 \mathrm{ng} / \mathrm{g}$ dust and $2929.3 \pm 3397.6 \mathrm{ng} / \mathrm{g}$ dust, respectively, at the time of pre-intervention and $1150.8 \pm 2422.4 \mathrm{ng} / \mathrm{g}$ dust and $2819.1 \pm 5601.4 \mathrm{ng} /$ $\mathrm{g}$ dust, respectively, after post-intervention. 


\section{Discussion}

The allergen levels of Der $\mathrm{f} 1$ were mostly detectable in CCCs in Korea whereas most those of Der $\mathrm{p} 1$ were below the detection limit. This finding is consistent with a previous study on Korean household environments. Sixty-five homes in 10 different cities across Korea were examined for species of dust mites. All 23 species of dust mites were observed, and the predominant mite found was Dermatophagoides farinae followed by $D$. pteronyssinus. Of the 23 species identified, $D$. farinae and $D$. pteronyssinus were found in $65.3 \%$ and $20.6 \%$ of the homes examined, respectively [18].

The HDM allergen concentrations found on bedding were significantly higher than those found on floors. The high Der 1 concentrations found on bedding echo the results of a study conducted in Brazil [9]. This previous study found that the Der 1 allergen levels were significantly higher among the bedding samples collected from DCCs than in the floor samples collected from elementary schools.

The HDM allergen levels on floors were positively correlated with the HDM allergen levels on bedding. This indicated that HDM allergens between samples from the floor and bedding dust may be transferred between them. Although the passive transfer of allergens between environments has previously been reported [19], the concentration of allergens that are passively transferred from bedding to the floors is unknown.

Several CCCs were at risk for sensitization or acute asthma development due to high levels of the HDM concentrations. Of the 38 CCCs studied, the Der 1 concentrations on the floors of 16 CCCs (42\%) exceeded $2000 \mathrm{ng} / \mathrm{g}$ dust, which is equivalent to $100 \mathrm{mites} / \mathrm{g}$ dust, and thus pose risks of sensitization to and development of asthma [20]. The Der 1 concentrations on the floors of one CCC exceeded $10000 \mathrm{ng} / \mathrm{g}$ dust, which is equivalent to 500 mites/g dust, and thus pose major risks of acute asthma development. The Der 1 concentrations on the bedding of 20 CCCs (53\%) exceeded $2000 \mathrm{ng} / \mathrm{g}$ dust and the Der 1 concentrations in four CCCs exceeded $10000 \mathrm{ng} / \mathrm{g}$ dust. Because nearly half of the Der 1 concentrations on both floors and bedding in CCCs exceeded the threshold for allergic sensitization, it is recommended that those CCCs control their dust mite concentrations, especially the facilities having susceptible children.

The high HDM allergen concentrations found in the present study complement those found in previous studies. The group 1 allergens (sum of Der $\mathrm{f} 1$ and Der $\mathrm{p} 1$ ) collected from mattresses, cushions, soft toys, and carpeted floors exceeded the threshold level of $2000 \mathrm{ng} / \mathrm{g}$ dust in 18 (44\%) of 41 DCCs studied in Germany [7]. The median concentration of group 1 allergens found in 137 samples collected from these 41 CCCs was
620 ng/g dust. Another study conducted in Sao Paulo, Brazil found that $67 \%$ of the samples collected from the floors and bedding in 15 DCCs and 15 preschools exceeded the threshold Der 1 levels [9]. The GMs of the Der 1 levels in DCCs and preschools reached $2600 \mathrm{ng} / \mathrm{g}$ dust and $6300 \mathrm{ng} / \mathrm{g}$ dust, respectively, in the bedding samples and $1300 \mathrm{ng} / \mathrm{g}$ dust and $1900 \mathrm{ng} /$ $\mathrm{g}$ dust, respectively, in the floor samples.

The HDM allergen levels found in this study were similar to those found among household environments in the metropolitan area of Seoul, Korea. The AM of the Der 1 concentrations found on bedding and mattresses from 100 apartments was found to be $1853.3 \pm 2566.8 \mathrm{ng} / \mathrm{g}$ dust [21]. Another study of the Seoul metropolitan area showed that the AMs of the Der 1 concentrations on bedding samples from homes with $(\mathrm{n}=2)$ and without $(\mathrm{n}=8)$ atopic children were $4170.1 \pm 922.3 \mathrm{ng} / \mathrm{g}$ dust and $1551.2 \pm 570.0$ $\mathrm{ng} / \mathrm{g}$ dust, respectively [22].

The Der 1 concentrations were not significantly associated with CCC characteristics. HDM allergen levels can be various by housing characteristics such as type of flooring and cleaning status [7,23]. Higher HDM allergen levels were observed in carpeted floors than smooth floors [7]. Another study reported that allergen levels of Der $\mathrm{p} 1$ on floors were higher with timber floor construction compared with concrete floor construction. [23]. In addition, recent cleaning status was associated with HDM allergen levels. In the present study, the type of flooring materials and weekly frequency of cleaning were not associated with HDM allergen concentrations on floors. In terms of the weekly frequency of cleaning, the most CCCs cleaned at least $5 \mathrm{~d}$ /wk with average cleaning days of $5.2 \pm 1.4 \mathrm{~d} / \mathrm{wk}$. Because of low variability of cleaning days with small samples size, identifying associations between cleaning status and Der 1 concentrations may be limited. Further study is needed to investigate factors associated with HDM allergens in CCCs with a large sample size.

The distribution of educational newsletters on bedding control significantly reduced the HDM allergen concentrations on both floors and bedding in the intervention group. The levels of HDM allergen concentrations in the floor and bedding samples from the intervention group decreased by $53.6 \%$ and $83.4 \%$, respectively. However, changes of the HDM allergen concentrations in the floor and bedding samples from the control group were not statistically significant. The detected significant reductions in the HDM allergen levels may be attributable to the fact that the parents of the intervention group followed the bedding control procedures outlined in the newsletters. This finding demonstrates that bedding control newsletter distribution practices may reduce the HDM allergen levels on both floors and bedding in CCCs.

Although the HDM allergen levels on floors significantly de- 
creased in the intervention group, those in the control group also decreased by $60.1 \%$. Higher decreased levels of the HDM allergen in the control group may be that one floor dust samples had a significant change rate of the HDM allergen levels between pre-and post-intervention. The Der 1 concentrations on floors in this CCC were $28588.8 \mathrm{ng} / \mathrm{g}$ dust before the intervention and $7037.8 \mathrm{ng} / \mathrm{g}$ dust after the intervention. Without the HDM allergen levels in the CCC, the decrease of the Der 1 concentrations in the control group was $38.8 \%$.

Reduction effects of HDM allergen levels by educational means have been previously reported. The number of mite positive samples was significantly reduced after educating 35 patients with an allergy to HDM for allergen avoidance [24]. Another study showed that after repeated education of housekeepers on indoor allergen reduction, the density of mites was reduced from 23.7 mites/g dust to 0.57 mites/g dust [16]. However, it remains uncertain that such a measure could lead to clinical effectiveness [25].

This is first study to apply an easy and simple method to reducing the HDM allergen levels in CCCs that involves the distribution of educational newsletters on household bedding control. Although it has already been proven that laundering bedding using hot water $\left(>55^{\circ} \mathrm{C}\right)$ and sun exposure can eliminate HDMs $[11,13]$, the present study provides the first evaluation of the effectiveness of educational newsletters that outline these mitigation strategies on reducing dust mite levels in CCCs.

This study presents several limitations. The HDM allergen levels were measured in the two classrooms that serve the youngest children. The HDM allergen concentrations may fluctuate between and within CCC rooms over time. In addition, the HDM levels found on CCC floors and bedding may be limited to representing dust mite levels in CCCs in Seoul. Another study showed that cushions, soft toys, and carpets can act as reservoirs for dust mites [7].

Another limitation is that the HDM allergen concentrations were measured at different seasons to assess the effectiveness of educational newsletters on reducing dust mite levels. As has been previously reported, the HDM allergen concentrations can vary by season [26]. A study in Seoul showed that Der $\mathrm{f} 1$ concentrations in the bedding dust at home increased from spring (April) to summer (July) and autumn (October) and decreased in winter (January) [27]. In the present study, the HDM allergens on floors in the control group decreased after the intervention, and this is may be due to seasonal variation. Because changes in the HDM concentrations on floors and bedding in the control group were not significant, the results from the effect of the newsletters on reducing HDM allergen levels may be reasonable.
The CCCs studied were not randomly assigned to the intervention and control groups. This non-randomized approach based on the HDM allergen levels may have some confounding effects. Because an allocation approach based on the HDM levels was used to divide the CCCs into two groups with similar HDM levels, confounding effects are likely minimal.

The study is also limited in that it was impossible to determine how many parents followed the written bedding control procedures outlined in the newsletters. The research team was only given information on the distribution status of the newsletters from the teachers of the targeted classrooms during the post-intervention sampling period. Although the present study did not determine how many parents followed the written procedures, the distribution of educational newsletters to parents may still be a reasonable strategy for reducing the HDM allergen concentrations in CCC settings.

The single repeated measurement of the HDM allergen levels conducted after the intervention may have provided limited information on sustainability. Future research needs to conduct multiple measurements of the HDM allergen levels to evaluate the long-term effects of newsletters on HDM allergen reduction.

The Der 1 concentrations on the floors and bedding of all of the 38 CCCs were measured. Of the CCCs studied, the HDM allergen concentrations on the bedding were significantly higher than those on the floors. Although the Der 1 concentrations in the control group did not significantly change, the Der 1 concentrations on the floors and bedding of the intervention group decreased significantly after the educational newsletters on bedding control were distributed to the parents of children in CCCs. The distribution of educational newsletters on bedding control to parents may serve as an effective means of controlling the HDM levels in CCCs.

\section{Acknowledgements}

This study was supported by the Seoul Municipal Government, Korea. The authors thank the directors and teachers of the childcare centers studied for their participation.

\section{Conflict of Interest}

The authors have no conflicts of interest with material presented in this paper.

\section{References}

1. Platts-Mills TA, Vervloet D, Thomas WR, Aalberse RC, Chapman $\mathrm{MD}$. Indoor allergens and asthma: report of the Third Internation- 
al Workshop. J Allergy Clin Immunol 1997;100(6 Pt 1):S2-S24.

2. Langley SJ, Goldthorpe S, Craven M, Morris J, Woodcock A, Custovic A. Exposure and sensitization to indoor allergens: association with lung function, bronchial reactivity, and exhaled nitric oxide measures in asthma. J Allergy Clin Immunol 2003;112(2):362368.

3. Wahn U, Lau S, Bergmann R, Kulig M, Forster J, Bergmann K, et al. Indoor allergen exposure is a risk factor for sensitization during the first three years of life. J Allergy Clin Immunol 1997;99(6 Pt 1):763-769.

4. Ministry of Health and Welfare. Child care statistics; 2011 [cited 2015 Apr 8]. Available from: http://stat.mw.go.kr/front/include/ download.jsp?bbsSeq=6\&nttSeq $=18457 \&$ atchSeq $=3024$ (Korean).

5. Zhang L, Chew FT, Soh SY, Yi FC, Law SY, Goh DY, et al. Prevalence and distribution of indoor allergens in Singapore. Clin Exp Allergy 1997;27(8):876-885.

6. Fernández-Caldas E, Codina R, Ledford DK, Trudeau WL, Lockey RF. House dust mite, cat, and cockroach allergen concentrations in daycare centers in Tampa, Florida. Ann Allergy Asthma Immunol 2001;87(3):196-200.

7. Engelhart S, Bieber T, Exner M. House dust mite allergen levels in German day-care centers. Int J Hyg Environ Health 2002;205(6): 453-457.

8. Munir AK, Einarsson R, Dreborg SK. Mite (Der p I, Der fI), cat (Fel $\mathrm{d} \mathrm{I})$ and $\operatorname{dog}(\mathrm{Can} \mathrm{fI})$ allergens in dust from Swedish day-care centres. Clin Exp Allergy 1995;25(2):119-126.

9. Rullo VE, Rizzo MC, Arruda LK, Solé D, Naspitz CK. Daycare centers and schools as sources of exposure to mites, cockroach, and endotoxin in the city of São Paulo, Brazil. J Allergy Clin Immunol 2002;110(4):582-588.

10. Frederick JM, Warner JO, Jessop WJ, Enander I, Warner JA. Effect of a bed covering system in children with asthma and house dust mite hypersensitivity. Eur Respir J 1997;10(2):361-366.

11. McDonald LG, Tovey E. The role of water temperature and laundry procedures in reducing house dust mite populations and allergen content of bedding. J Allergy Clin Immunol 1992;90(4 Pt 1):599608.

12. Miller J, Miller A. Ten minutes in a clothes dryer kills all mites in blankets. J Allergy Clin Immunol 1996;97(1):423.

13. Tovey ER, Woolcock AJ. Direct exposure of carpets to sunlight can kill all mites. J Allergy Clin Immunol 1994;93(6):1072-1074.

14. Yu CH, Yiin LM, Tina Fan ZH, Rhoads GG. Evaluation of HEPA vacuum cleaning and dry steam cleaning in reducing levels of polycyclic aromatic hydrocarbons and house dust mite allergens in carpets. J Environ Monit 2009;11(1):205-211.
15. Portnoy J, Miller JD, Williams PB, Chew GL, Miller JD, Zaitoun F, et al. Environmental assessment and exposure control of dust mites: a practice parameter. Ann Allergy Asthma Immunol 2013;111(6): 465-507.

16. Jeong KY, Lee IY, Lee J, Ree HI, Hong CS, Yong TS. Effectiveness of education for control of house dust mites and cockroaches in Seoul, Korea. Korean J Parasitol 2006;44(1):73-79.

17. Yong TS, Jeong KY. Review on ecology of house dust mites in Korea and suggestion of a standard survey method. Pediatr Allergy Respir Dis 2011;21(1):4-16

18. Ree HI, Jeon SH, Lee IY, Hong CS, Lee DK. Fauna and geographical distribution of house dust mites in Korea. Korean J Parasitol 1997; 35(1):9-17.

19. De Lucca SD, O'meara TJ, Tovey ER. Exposure to mite and cat allergens on a range of clothing items at home and the transfer of cat allergen in the workplace. J Allergy Clin Immunol 2000;106(5):874879.

20. Dust mite allergens and asthma-a worldwide problee allergens and asthma-a worldwide problem. J Allergy Clin Immunol 1989;83(2 Pt 1):416-427.

21. Kwon MH, Jang SK, Ryu JM, Seo SY, Won SR, Jung SJ, et al. A study on management of major indoor air pollutants by house type in Korea (I): indoor air pollution and health effects in residential apartment. Incheon: National Institute of Environmental Research; 2009, p. 66 (Korean).

22. Shon JR, Choi DW, Baik YK. Concentraion of dust mite allergen of bedclothing and indoor air in house. J Korean Soc Living Environ Syst 2006;13(3):237-240 (Korean).

23. Wickens K, Martin I, Pearce N, Fitzharris P, Kent R, Holbrook N, et al. House dust mite allergen levels in public places in New Zealand. J Allergy Clin Immunol 1997;99(5):587-593.

24. Cingi C, Cakli H, Miman O, Altin F, Aycan O, Atambay M, et al. Correlation of environmental mite levels and the symptoms of allergic rhinitis regarding the efficacy of preventive education. Allergol Immunopathol (Madr) 2007;35(6):243-247.

25. van Boven FE. Effectiveness of mite-impermeable covers: a hypothesis-generating meta-analysis. Clin Exp Allergy 2014;44(12):14731483.

26. Platts-Mills TA, Hayden ML, Chapman MD, Wilkins SR. Seasonal variation in dust mite and grass-pollen allergens in dust from the houses of patients with asthma. J Allergy Clin Immunol 1987;79(5): 781-791.

27. Kim JH, Choi SY, Lee IY, Lee YW, Yong TS, Kim CW, et al. Seasonal variation of house dust mite and its influence on the inhabitant health. Korean J Asthma Allergy Clin Immunol 2006;26(1):27-34 (Korean). 